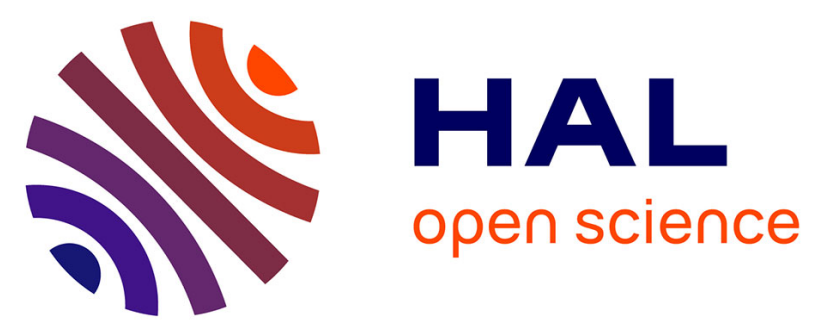

\title{
Bone texture analysis on dental radiographic images: results with several angulated radiographs on the same region of interest
}

Yves Amouriq, Jean-Pierre Guédon, Nicolas Normand, Aurore Arlicot, Yassine Ben Hdech, Pierre Weiss

\section{To cite this version:}

Yves Amouriq, Jean-Pierre Guédon, Nicolas Normand, Aurore Arlicot, Yassine Ben Hdech, et al.. Bone texture analysis on dental radiographic images: results with several angulated radiographs on the same region of interest. SPIE Medical Imaging 2011: Biomedical Applications in Molecular, Structural, and Functional Imaging, Feb 2011, Lake Buena Vista, United States. pp.796525, 10.1117/12.878152 . hal-00637547

\section{HAL Id: hal-00637547 https://hal.science/hal-00637547}

Submitted on 15 Feb 2012

HAL is a multi-disciplinary open access archive for the deposit and dissemination of scientific research documents, whether they are published or not. The documents may come from teaching and research institutions in France or abroad, or from public or private research centers.
L'archive ouverte pluridisciplinaire HAL, est destinée au dépôt et à la diffusion de documents scientifiques de niveau recherche, publiés ou non, émanant des établissements d'enseignement et de recherche français ou étrangers, des laboratoires publics ou privés. 


\title{
Bone texture analysis on dental radiographic images : results with several angulated radiographs on the same region of interest.
}

\author{
Yves AMOURIQ ${ }^{* a b c}$, Jeanpierre GUEDON ${ }^{\text {a }}$, Nicolas NORMAND $^{\text {a }}$, \\ Aurore ARLICOT ${ }^{\text {a }}$, Yassine BENHDECH ${ }^{\mathrm{a}, \mathrm{d}}$, Pierre WEISS ${ }^{\mathrm{c}}$. \\ ${ }^{a}$ IRCCyN/IVC - UMR CNRS 6597- École Polytechnique University of Nantes. \\ Rue christian Pauc, La Chantrerie, BP 50609, 44306 Nantes - France \\ ${ }^{\mathrm{b}}$ ERT 2004, UMR_S 791-Odontology dpt University of Nantes. \\ 1 Place A. Ricordeau 44042 Nantes - France \\ ${ }^{\mathrm{c}}$ LIOAD, INSERM, UMR S791 - Odontology dpt University of Nantes, \\ 1 place A Ricordeau F44042 Nantes - France \\ ${ }^{\mathrm{d}}$ QualiFormeD, 14 rue de la vieille horloge, 85000 La Roche sur Yon, France
}

\begin{abstract}
Bone microarchitecture is the predictor of bone quality or bone disease. It can only be measured on a bone biopsy, which is invasive and not available for all clinical situations. Texture analysis on radiographs is a common way to investigate bone microarchitecture. But relationship between three-dimension histomorphometric parameters and twodimension texture parameters is not always well known, with poor results. The aim of this study is to performed angulated radiographs of the same region of interest and see if a better relationship between texture analysis on several radiographs and histomorphometric parameters can be developed. Computed radiography images of dog (Beagle) mandible section in molar regions were compared with high-resolution micro-CT (Computed-Tomograph) volumes. Four radiographs with $27^{\circ}$ angle (up, down, left, right, using Rinn ring and customized arm positioning system) were performed from initial radiograph position. Bone texture parameters were calculated on all images. Texture parameters were also computed from new images obtained by difference between angulated images. Results of fractal values in different trabecular areas give some caracterisation of bone microarchitecture.
\end{abstract}

Keywords: bone microarchitecture, Texture analysis, Computed Radiograph, Micro-Computed-Tomography, fractal dimension.

\section{INTRODUCTION}

The BIOREGOS2 project aims to study the bone from several point of views. Fourteen academic research labs in Nantes, Angers and Le Mans are involved in this project from the material characterization, the mechanical, the chemical, and the medical intersections.

Bone microarchitecture is the predictor of bone quality or bone disease like osteoporosis. The study of microarchitecture is based on the measure of width, number, and separation of trabeculae as well as on their spatial organization [1,2]. It can only be measured on a bone biopsy, which is invasive and not available for all clinical situations. Bone texture analysis on radiographs is a common way to investigate bone microarchitecture. But relationship between threedimension (denoted 3D) histomorphometric parameters and two-dimension (denoted 2D) texture parameters is not always well known, with poor results. [3,4]. This is the long term objective that we look for.

* $\quad$ yves.amouriq@univ-nantes.fr, phone +336087664 45 
In this paper, the three different image acquisitions of the same scene are described in section 2. Section 3 presents multiple results gained during the year from the cross study of microarchitecture and the corresponding 2D texture. This paper specifically focuses onto the so-called fractal dimension. This tool is easily implemented in $2 \mathrm{D}$ both for the projection radiograph as well as for the slices obtained from the micro scanner. The reader must be aware that it is very easy to derive this value from any binary image without having a true understanding of its "reality". However, in the context of bone microarchitecture, this dimension is interesting to investigate because there is a direct link between its evaluation and the local geometry.

\section{MATERIALS AND METHODS}

\subsection{Parameters and Figure of Merit}

The aim of this study is to start from different angulated radiographs [5,6] of the same bone Region Of Interest (ROI) and see if a better relationship between texture analysis on several radiographs and histomorphometric parameters derived from micro CT can be developed. In this paper, we have used ImageJ software as well as Octave software in order to compute the different results.

Three texture parameters are often used for bone characterization:

- Hmean parameter : this is a fractal parameter. It can be derived from a geometric point of view by counting the numbers of disks inside boxes of several dimensions. Notice that this algorithm does not give a very precise idea of a real fractal dimension (this can be only obtained from a multiresolution analysis). However, this algorithm fits very well the structure of the bone composed of trabeculaes. This is why we keep this algorithm in this paper (we also keep the fractal word even if probably denaturated in this context). Fractal dimension of trabecular bone projection texture is especially related to connectivity and porosity. According to different authors $[3,8,9]$, the description of the fractal shapes is given by a single parameter, $\mathrm{H}$ (Hurst exponent), related to the fractal dimension, $\mathrm{D}$, by $\mathrm{H}=2-\mathrm{D}$. The higher $\mathrm{H}$ is, the smaller the roughness of the path.

- Run-length : this parameter actually corresponds to the previous parameter but in a 1D sense. It corresponds to counting on a line the length of series of black or white values. In order words, this is the "1D fractal" when the box size is only one pixel hight.

- Co-occurrence [7] parameters. These parameters extracted from Aralick Co-occurences matrices are often difficult to jointly interpret for several directions.

Notice that the $27^{\circ}$ was derived to allows a specific relationship between radiographs and micro CT. This angle corresponds to a discrete angle in a rectangle triangle where the two orthogonal sides are of relative dimension 2 and 1. This situation gives a Mojette transform angle [10] which can be easily computed from the 3D volume in any directions.

\subsection{Digital radiographs}

Computed radiography (CR, Kodak RVG system, Rochester, New-York, USA) images of a dog (Beagle) mandible section in molar regions with one tooth were compared with high-resolution micro-CT volumes (denoted $\mu \mathrm{CT}$ ) using a Computed-Tomography Skyscan 1072, Kontich, Belgium, voxel size about $19 \mu \mathrm{m}$. We used also D3A medical systems radiograph (digital radiography system, D3A, Orléans, France) to perform the four same $27^{\circ}$ angulated radiographs using another customized positioning system giving the $27^{\circ}$ inclination. A Region Of Interest (ROI) including trabecular and cortical bone was determined between tooth roots.

For this study, a Rinn ring (Dentsply) was customized for its arm positioning system. It allows to locate the sample on a specific 3D geometric position within the 2-1 angle relationship mentioned above. Figure 1 presents the customized Rinn ring (fig. 1 -a) as well as a digital radiograph (fig. 1-b) showing a 2D region of interest (2D ROI) corresponding to the trabecular bone that has also been reconstructed in 3D (fig. 1-c) from the micro CT after a manual extraction of the 3D ROI corresponding to the trabecular bone (fig. 1-d). 


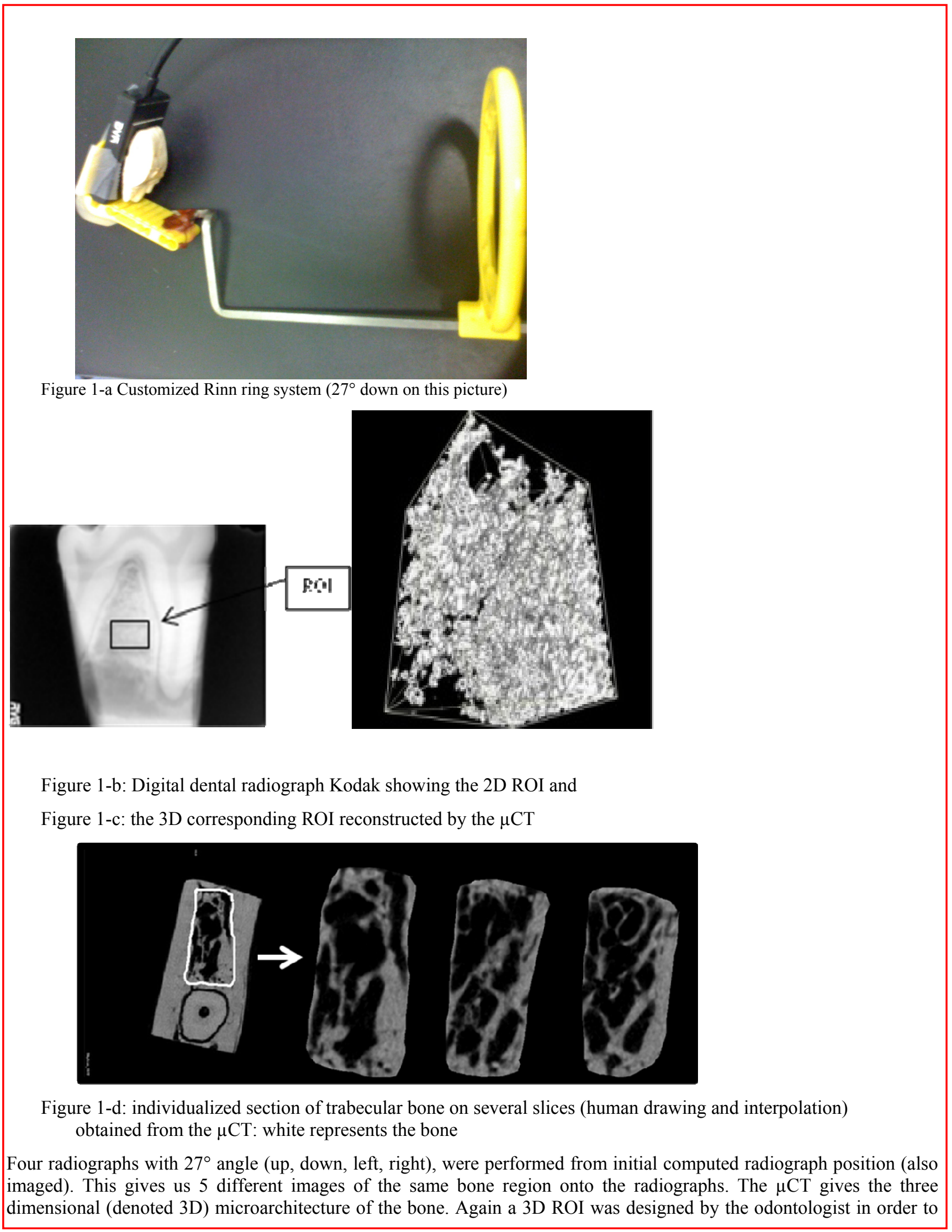


keep only the bone region. It must be mentioned that this 3D ROI only retains the trabecular bone and does not take into account the cortical bone.

Therefore, we have both the texture of the bone onto the radiograph and its corresponding 3D microarchitecture.

\subsection{Texture parameters and fractal dimension}

The D3A medical system allows texture analysis (double exposure) on radiographs with Hmean, run-length and cooccurrence results. We performed 8 times the measure on the ROI and on all angulated radiographs.

On radiographs issued from Kodak RVG system and from micro-CT, difference between angulated radiographs was calculated using Image $\mathbf{J}$ software. After binarisation of the ROI, fractal dimension of the difference image was also calculated.

According to X-ray angulation on RVG radiograph, there is a displacement of the ROI on the pictures produced by the $27^{\circ}$ angulation. This displacement was calculated as an equivalent translation (instead of the true $3 \mathrm{D}$ rotation) and images were cropped to perform difference on the same zone.

Several ROI with different bone microarchitecture (according to $\mu \mathrm{CT}$ ) were used.

\subsection{Bone microarchitecture parameters}

Bone microarchitecture parameters on the trabecular zone of the ROI were calculated using $\mu \mathrm{CT}$ software (CT AN,Skyscan 1072, Kontich, Belgium).

\section{RESULTS}

The customized Rinn ring allowed us to obtain images of the same ROI (region of interest) with precise $27^{\circ}$ angulation in all directions (angulation of generator, bone and $\mathrm{X}$ ray captor fixed). These images are presented on figure 2 for the centered and $27^{\circ}$ up displacment. Figure 3 presents images where a lateral $27^{\circ}$ (right and left) rotation from the centered position was performed.

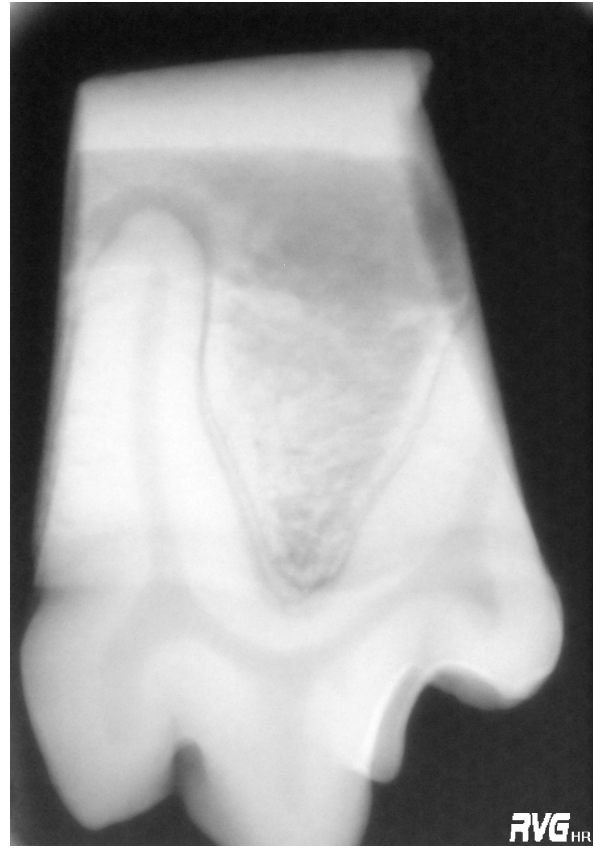

Figure 2 : a)RVG $0^{\circ}$ (centered)

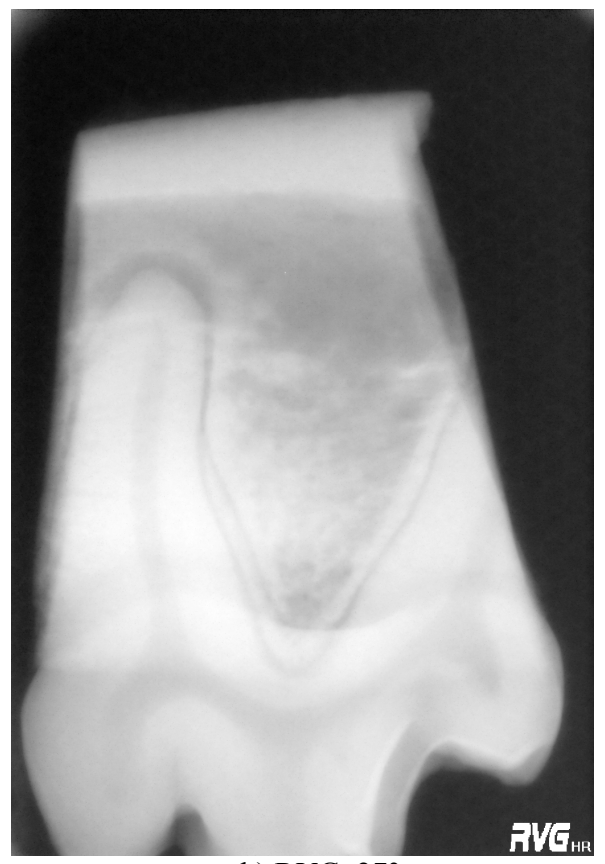

b) RVG $27^{\circ}$ up 


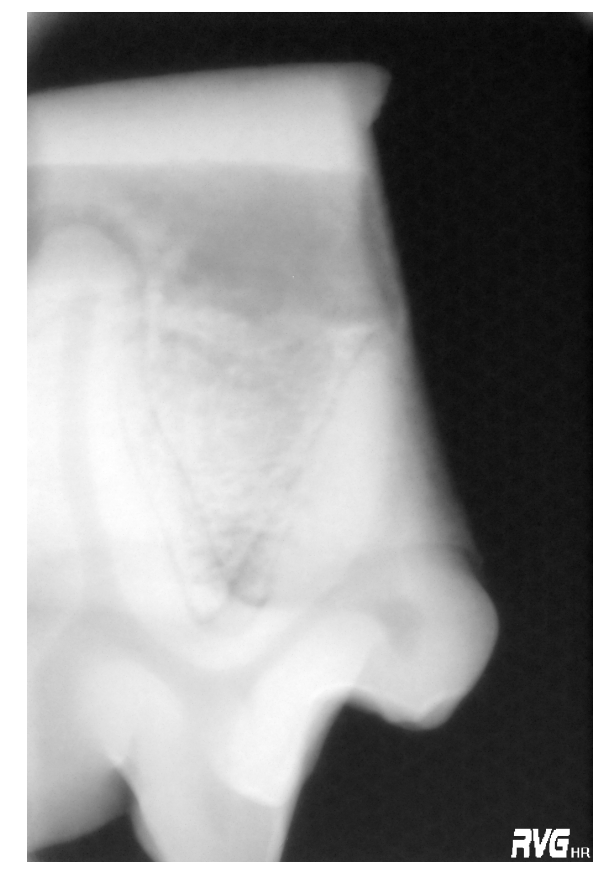

Figure 3 : a) RVG $27^{\circ}$ left lateral

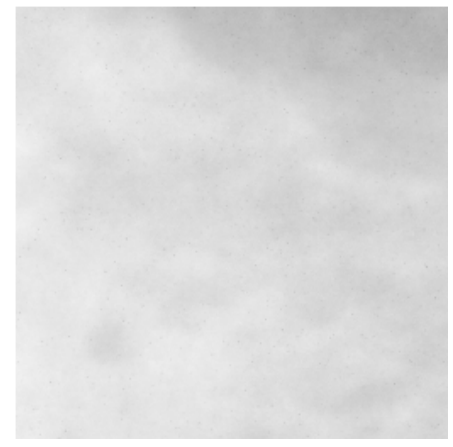

Figure $4:$ a) trabecular ROI $0^{\circ}$

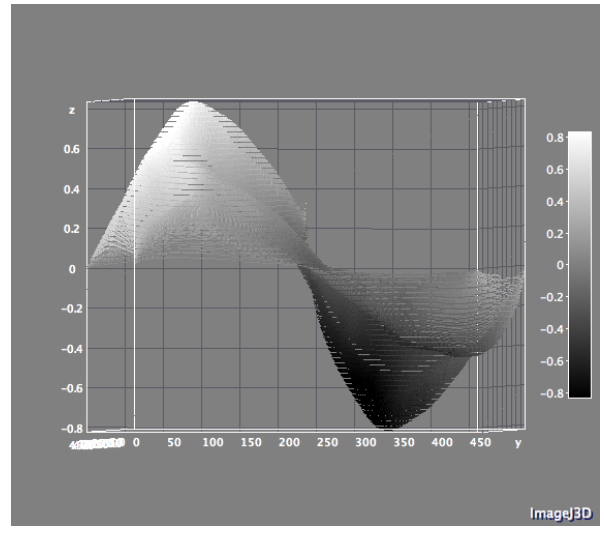

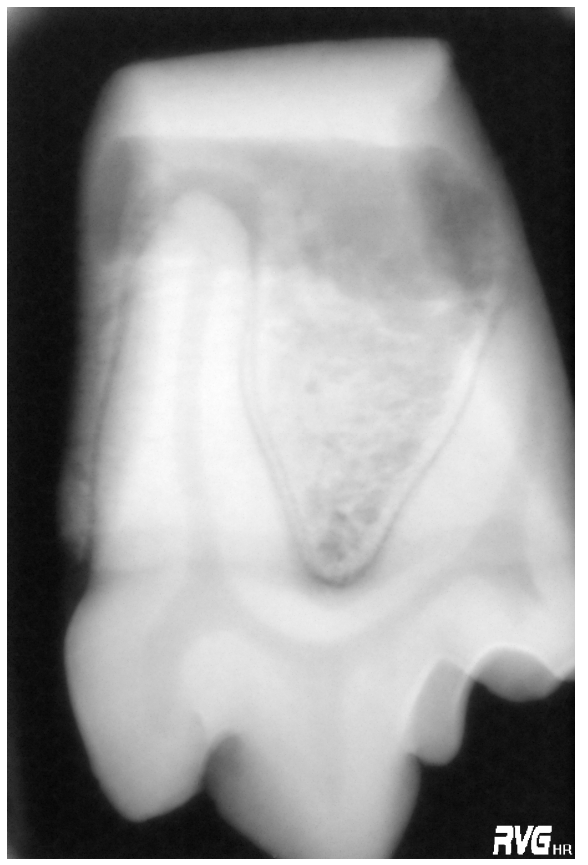

b) RVG $27^{\circ}$ right lateral

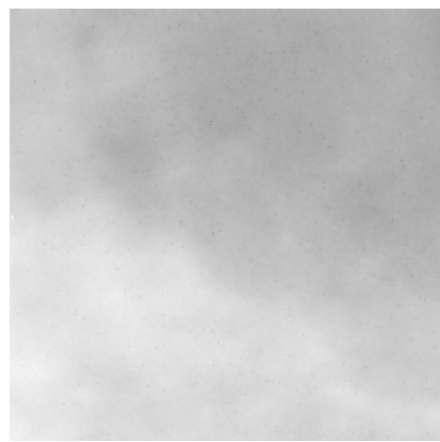

b) trabecular ROI $27^{\circ}$ up

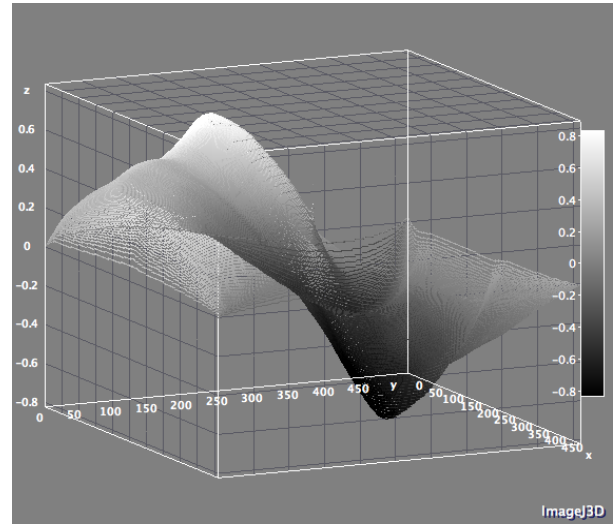

Figure $4 \mathrm{c}: 2 \mathrm{D}$ correlation of $256 \times 256$ trabecular bone ROI : ( $0^{\circ}$ - right lateral $\left.27^{\circ}\right)$ and $\left(0^{\circ}\right.$ and $27^{\circ}$ up $)$ ROIs 
Figure 4-c presents the 2D correlation between centered image (ROI in fig 4-a issued from fig.2-a) and right lateral (ROI in fig 4-b issued from fig 3-b). Instead of doing this computation onto the whole image, only a 256 square ROI corresponding to the trabecular bone region was used. After equalization, these two ROI exhibits the same textures of a lumpy background style.

An interesting point of view is given by the displacement in one direction or another one. The $27^{\circ}$ rotation gives an idea of the $\mathrm{z}$ dimension size of the trabecular region that can be estimated.This was measured and correlated with the 3D micro CT ground truth.

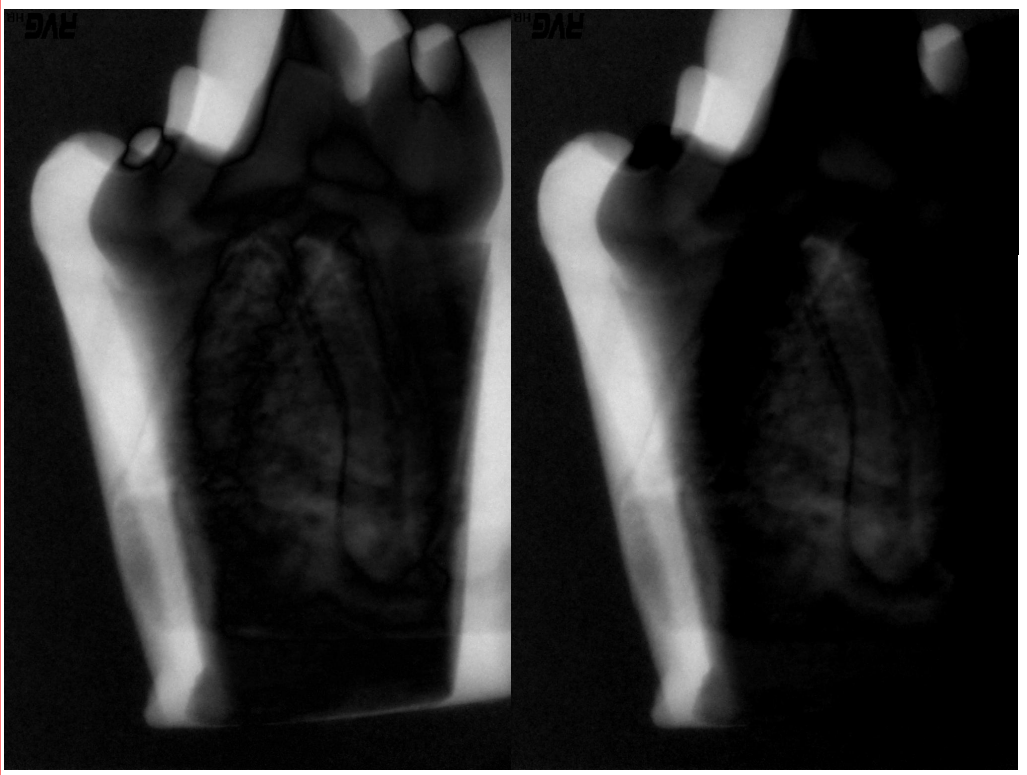

Figure 5 Difference between $0^{\circ}$ and $27^{\circ}$ left (RVG) $\quad$ Subtraction 0 and $27^{\circ}$ left $(\mathrm{RVG})$ and $27^{\circ}$ left (RVG)

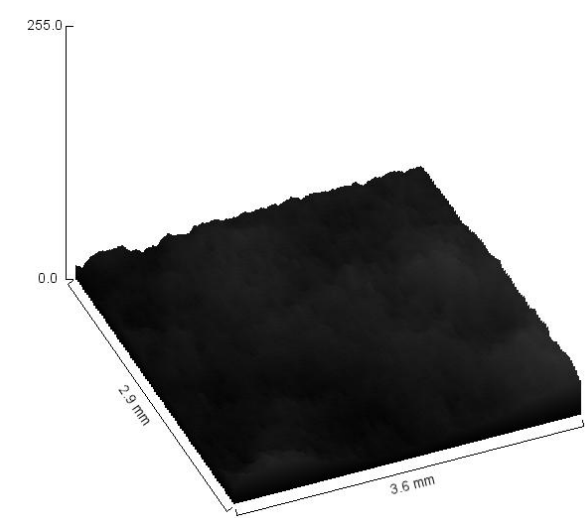

Surface plot on difference 0

Figure 5 shows the difference between centered and $27^{\circ}$ images (L1 norm or absolute difference). The simple subtraction between images is also presented but was useless. The trabecular ROI of the difference is presented on the surface plot: it exhibits a very small range of values and the same kind of lumpy background as the ROIs by itself. Doing the same computation with images $27^{\circ}$ left and $27^{\circ}$ right also gives this kind of difference image still with a small grey level range.

From $0^{\circ}$ radiograph and $27^{\circ}$ left radiograph, the displacement was measured about $3,01 \mathrm{~mm}$. The knowledge of the angulation and displacement allows for determination of mandible section thickness. This value can be of importance for in vivo experimentation. 


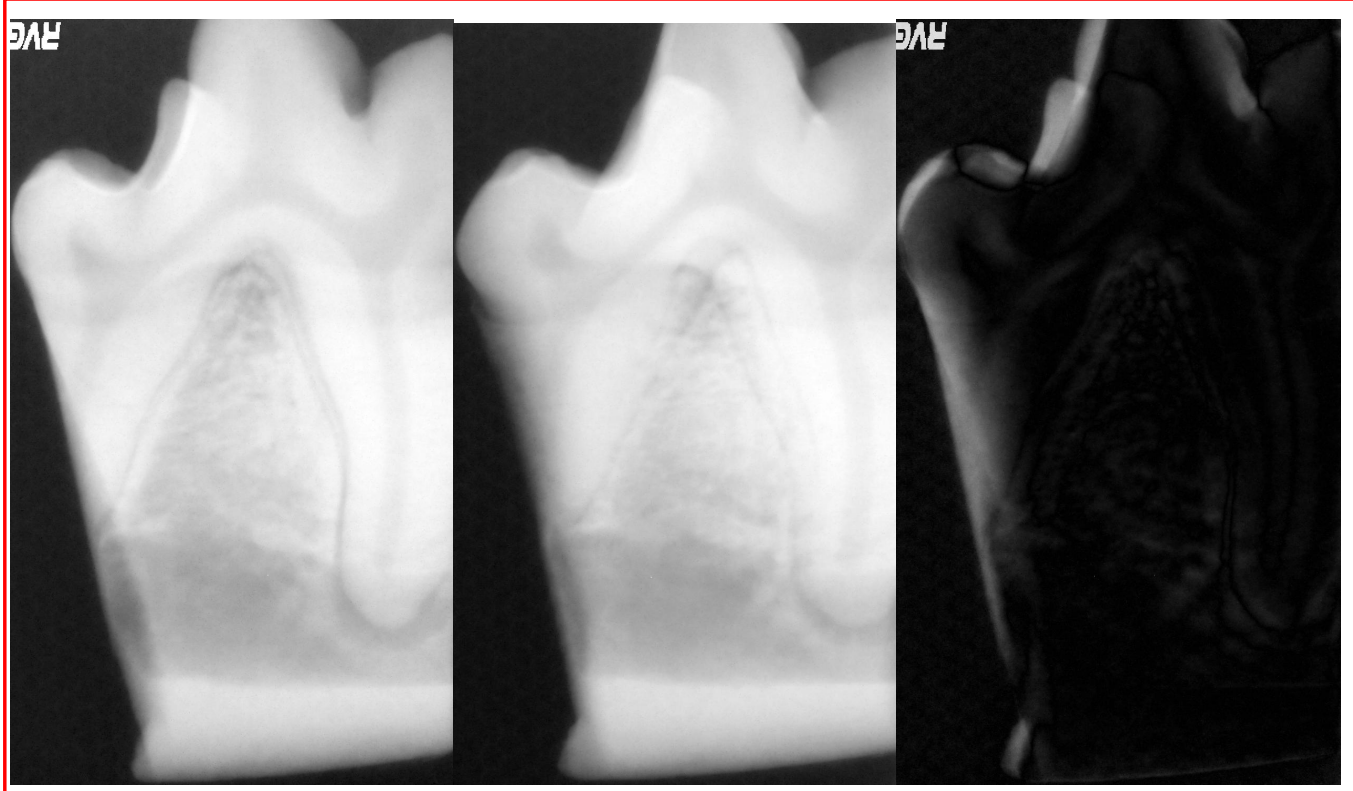

Figure 6 Difference from 0 and $27^{\circ}$ left images after a correction of displacement

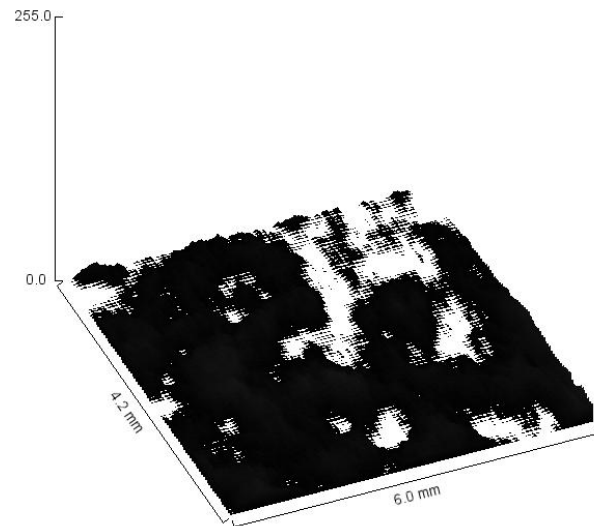

Figure 7 Plot of the difference from 0 and $27^{\circ}$ left images after a correction of displacement

After the displacement has been corrected (as in Figure 6), the difference computed between the two images showed in Figure 7 regions zero valued. This is correct to have at least some regions (both trabecular bone and trabecular separation) that are superimposed and dissapear with the difference.

The bone parameter extracted from the micro CT are recalled in Table 1 below. The average trabecular thickness is around $0.6 \mathrm{~mm}$ while the average trabecular separation is $0.5 \mathrm{~mm}$. One can find 1.05 trabeculae per mm. These measures are essential since they explain a relative organisation of the micro architecture as well as they lead to the main opinion for the medical viewpoint. The fractal dimension computed here will be discussed later on.

Next are presented Table 2 and Table 3 where the fractal dimension where computed. However, instead of taking the original ROI, here we first computed the difference image between two ROI images of different orientations. In Table 2 , the computations were made on centered and $27^{\circ}$ acquired radiographs. On Table 3 , we computed DRR from the micro CT stack for different orientations. Thus in the second case, there is no need to correct for displacement since the center of the volume is always projected on the center of the projection. Figure 8 shows two images obtained by this DRR procedure which involves the Mojette projector at angle $(2,1)$ corresponding to the $27^{\circ}$ angle. 
Table 1: bone parameters extracted from the micro CT

\begin{tabular}{|l|l|l|}
\hline Tissue volume & TV & $57.2 \mathrm{~mm}^{\wedge} 3$ \\
\hline Bone volume & BV & $39.43 \mathrm{~mm}^{\wedge} 3$ \\
\hline Percent bone volume & BV/TV & $68.94 \%$ \\
\hline Tissue surface & TS & $114.17 \mathrm{~mm}^{\wedge} 2$ \\
\hline Bone surface & BS & $229.24 \mathrm{~mm}^{\wedge} 2$ \\
\hline Intersection surface & i.S & $93.16 \mathrm{~mm}^{\wedge} 2$ \\
\hline Bone surface / volume ratio & BS/BV & $5.81 / \mathrm{mm}$ \\
\hline Bone surface density & BS/TV & $4.011 / \mathrm{mm}$ \\
\hline Trabecular pattern factor & Tb.Pf & $-1.221 / \mathrm{mm}$ \\
\hline Structure model index & SMI & -0.33 \\
\hline Trabecular thickness & Tb.Th & $0.65 \mathrm{~mm}$ \\
\hline Trabecular number & Tb.N & $1.05661 / \mathrm{mm}$ \\
\hline Trabecular separation & Tb.Sp & $0.5035 \mathrm{~mm}$ \\
\hline Degree of anisotropy & DA & $2.226(0,55070)$ \\
\hline Fractal dimension & FD & 2.09 \\
\hline
\end{tabular}

Table 2 Fractal dimension of ROI on $\mu \mathrm{CT}$ radiographs

\begin{tabular}{|c|c|c|c|}
\hline \multicolumn{4}{|c|}{ Micro CT radiographs(DRR) - ROI on the difference between 0 et $27^{\circ}$} \\
\hline name & Position (left top pixel) & size & $\begin{array}{l}\text { Fractal } \\
\text { value }\end{array}$ \\
\hline ROI1 & $\mathrm{X}=320, \mathrm{Y}=360$ & $128 / 128$ pixel & 1,9066 \\
\hline ROI2 & $\mathrm{X}=320, \mathrm{Y}=360$ & 194/194 pixel & 1,7608 \\
\hline ROI3 & $\mathrm{X}=360, \mathrm{Y}=300$ & $128 / 128$ pixel & 1,6445 \\
\hline ROI4 & $\mathrm{X}=360, \mathrm{Y}=428$ & $128 / 128$ pixel & 1,7379 \\
\hline ROI5 & $X=360, Y=300$ & $128 / 256$ pixel & 1,7299 \\
\hline
\end{tabular}

Table 3 Fractal dimension of ROIs difference on $\mu$ CT radiographs DRR

\begin{tabular}{|c|c|c|c|c|c|}
\hline $\begin{array}{l}\text { Difference of } \\
\text { images }\end{array}$ & ROI number & Fractal value & Difference of images & ROI number & Fractal value \\
\hline Diff $0-3,675^{\circ}$ & ROI1 & 1,985 & Diff $0-13,5^{\circ}$ & ROI1 & 1,9379 \\
\hline Diff $0-3,675^{\circ}$ & ROI2 & 1,8143 & Diff $0-13,5^{\circ}$ & ROI2 & 1,7627 \\
\hline Diff $0-6,75^{\circ}$ & ROI1 & 1,9491 & Diff $0-20,25^{\circ}$ & ROI1 & 1,9012 \\
\hline Diff $0-6,75^{\circ}$ & ROI2 & 1,8144 & Diff $0-20,25^{\circ}$ & ROI2 & 1,7202 \\
\hline Diff $0-3,675^{\circ}$ & ROI1 & 1985 & Diff $0-27^{\circ}$ & ROI1 & 1,9066 \\
\hline Diff $0-3,675^{\circ}$ & ROI2 & 1,8143 & Diff $0-27^{\circ}$ & ROI2 & 1,7608 \\
\hline Diff $0-6,75^{\circ}$ & ROI1 & 1,9491 & Diff $0-33,75^{\circ}$ & ROI1 & 1,9109 \\
\hline Diff $0-6,75^{\circ}$ & ROI2 & 1,8144 & & & \\
\hline
\end{tabular}




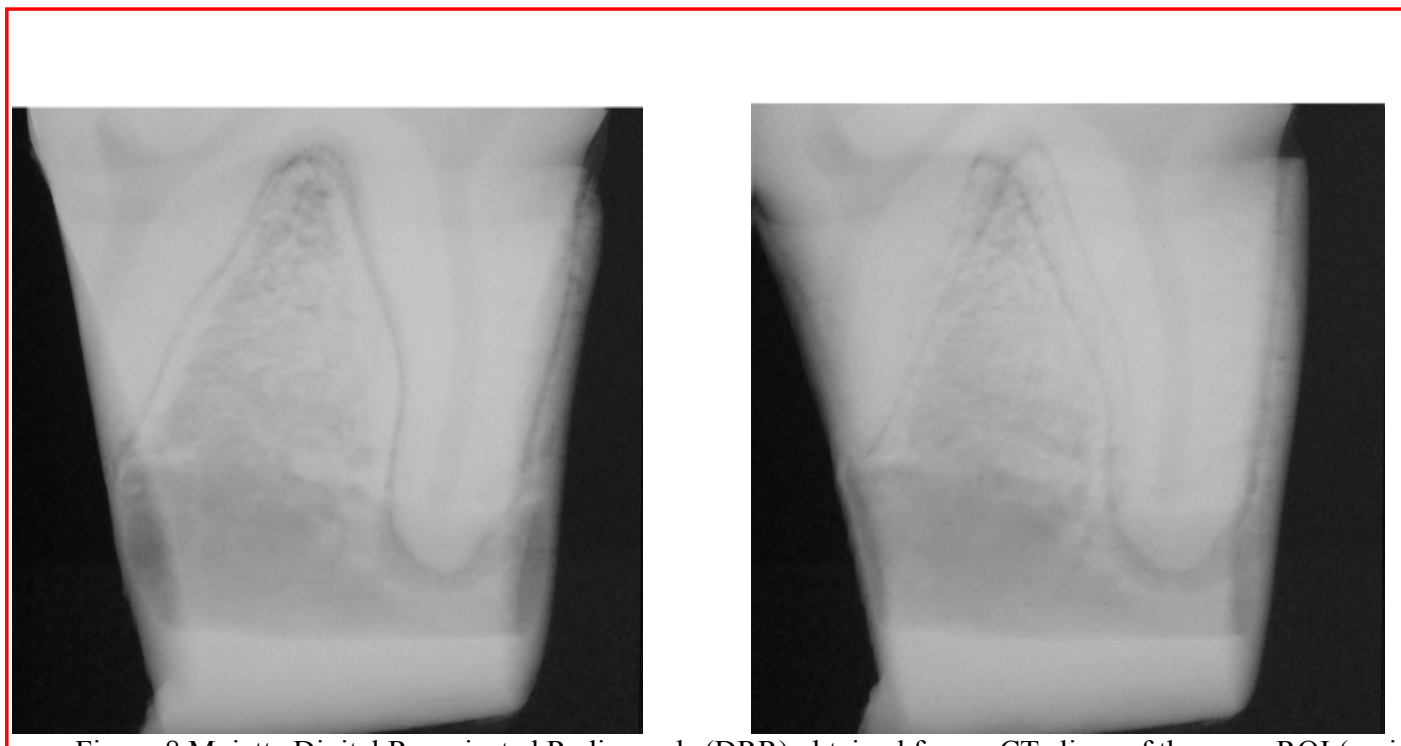

Figure 8 Mojette Digital Reprojected Radiographs(DRR) obtained from $\mu$ CT slices of the same ROI (region of interest) with precise $0^{\circ}$ and $27^{\circ}$ angulation (rotation of bone, generator and $\mathrm{X}$ ray captor fixed).

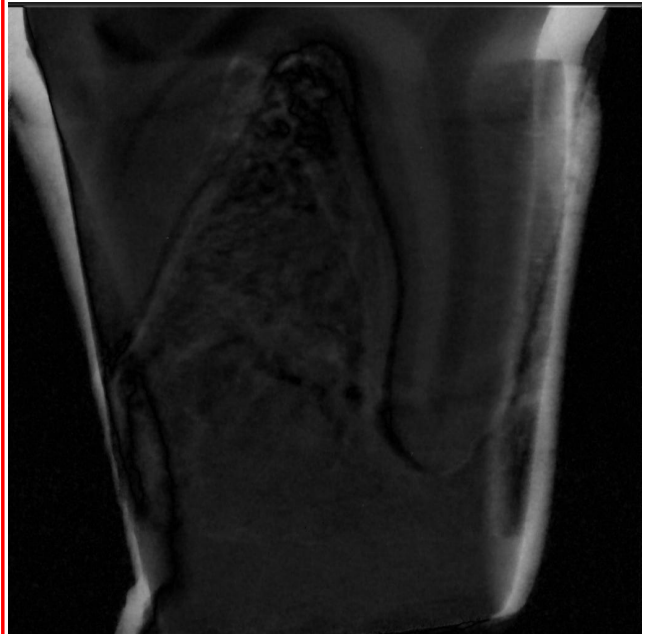

Fig 9-a Difference 0 and $27^{\circ} \operatorname{left}(\mu \mathrm{CT})$

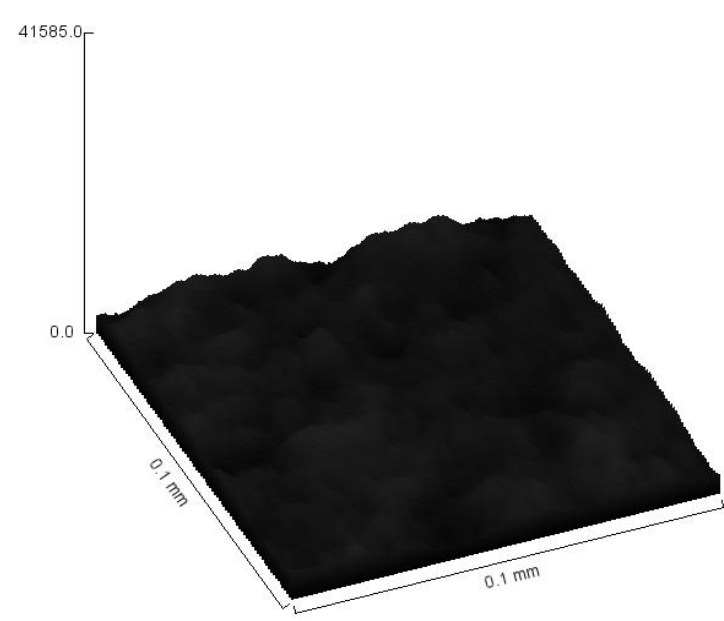

Fig 9-b: Surface plot on difference 0 and $27^{\circ}$ left $(\mu \mathrm{CT})$

Figure 9 shows the difference image of the 2 images presented in figure 8 . The plot of the ROI exhibits no valley as it was the case in figure 7. This difference image of the ROI can be characterized by the same lumpy background found in figure 5. This was the case for all DRR ROI differences images. Thus, we computed the fractal value of all these differences ROI and the results are presented in Table 3.

In order to compute the fractal value, all these images were finally binarized (with different thresholds without significant changes).As shown in Table 3, the fractal dimension of a ROI of a difference of angulated radiographs is always the same whatever is the angulation (between $3,675^{\circ}$ and $33,75^{\circ}$ ). In the other hand, the fractal dimension of different ROI of the same difference of angulated radiographs is not the same, especially according to different bone microrchitecture ( $\mu \mathrm{CT}$ determination).

Therefore, the fractal dimension of a ROI of a difference of angulated radiographs seems to be a constant parameter correlated to bone microarchitectecture. 
This parameter cannot be correlated to Hmean, because this a fractal dimension of the difference image. Without double exposure system, this parameter can give information on bone micro-architecture. Correlated texture analysis on several angulated images gave better informations on bone micro-architecture. The influence of number of angulated radiographs (between 3 and 5), of the angle $\left(27^{\circ}\right)$ will now be studied for further works.

These results allows for completing the analysis between the 2D radiographs that can be obtained in a routine manner from patients and the 3D underlying bone structure.

\section{CONCLUSION}

Improvement of measurement of texture parameters with several angulated radiographs could allowed a better correlation with bone architecture descriptor and an easy diagnostic. Links between 2D radiographs and 3D micro CT for bone characterization have already been studied. However, the digital tools used here and the high correlations obtained allows for optimistic future characterization on alive bone through only radiographs. The fractal dimension of a difference of angulated radiographs is a constant parameter that can be correlated to bone microarchitectecture. The way of correlation needs further works. Angulated radiographs allowed a better correlation between texture parameters and bone microarchitecture. 3 to 5 angulated radiographs could be an easy way to provide a good knowledge of bone microarchitechture, obtained in a routine manner from patients in a lot of medical applications.

\section{ACKNOWLEDGEMENTS}

This research has been made under the program BIOREGOS2 with a grant from Région Pays de la Loire.

\section{REFERENCES}

[1] Dalle Carbonare L, Valenti MT, Bertoldo F, Zanatta M, Zenari S, Realdi G, Lo Cascio V, Giannini S.Bone microarchitecture evaluated by histomorphometry. Micron. ;36_7-8):609-16. (2005)

[2] Müller R, Hildebrand T, Häuselmann HJ, Rüegsegger P. In vivo reproducibility of three-dimensional structural properties of noninvasive bone biopsies using 3D-pQCT. J Bone Miner Res. Nov;11(11):1745-50. (1996)

[3] Guggenbuhl P, Bodic F, Hamel L, Baslé MF, Chappard D. Texture analysis of X-ray radiographs of iliac bone is correlated with bone micro-CT. Osteoporos Int. ;17(3):447-54. (2006)

[4] Southard TE, Southard KA. Detection of simulated osteoporosis in maxillae using radiographic texture analysis. IEEE Trans Biomed Eng ;43-2:123-32. (1996)

[5] Garcia-Figueroa MA, Raboud DW, Lam EW, Heo G, Major PW. Measurement of mesiodistal root angulation for panoramic images and the effect of buccolingual root angulation. Int Orthod. ;7-1:15-30. (2009)

[6] Mayer Y, Machtei EE. Divergence correction associated with implant placement: a radiographic study. Int J Oral Maxillofac implants ;24-6:1033-9. (2009)

[7] Galloway MM. Texture analysis using gray level run lengths. Comput Graph Image Proc ;4:172-179. (1975)

[8] Pothuaud L, Benhamou CL, Porion P, Lespessailles E, Harba R, Levitz P. Fractal dimension of trabecular bone projection texture is related to three-dimensional microarchitecture. J Bone Miner Res. Apr;15-4:691-9. (2000)

[9] Lespessailles E, Gadois C, Lemineur G, Do-Huu JP, Benhamou L. Bone Texture Analysis on Direct Digital Radiographic Images: Precision Study and Relationship with Bone Mineral Density at the Os Calcis. Calcif Tissue Int; 80:97-102. (2007)

[10] Guédon, Jeanpierre et al, The Mojette transform, theory and applications, edited by Jeanpierre Guédon, ISTEWILEY Publishers, London \& New-York (2009).

[11] Bodic, F., Amouriq, Y., Gauthier, O., Gayet-Delacroix, M., Bouler, J.M., Daculsi, G. and Hamel, L.,"Computed tomography assessment of alveolar filling with an injectable bone substitute," J Mater Sci Mater Med 13-10, 953-958 (2002).

[12] Jennane, R., Harba, R., Lemineur, G., Bretteil, S., Estrade, A., Benhamou, C., L., "Estimation of the 3D selfsimilarity parameter of trabecular bone from its 2D projection," Medical Image Analysis 11, 91-98 (2007).

7965 - 76 V. 6 (p.10 of 10) / Color: No / Format: A4 / Date: 2011-01-29 01:49:22 AM

SPIE USE:

DB Check,

Prod Check, Notes: 